\title{
Infrared thermography applied for experimental investigation of thermomechanical couplings in Gum Metal
}

\author{
by K.M. Golasiński, E. Pieczyska*, M. Staszczak*, T. Furuta** and S. Kuramoto*** \\ * Institute of Fundamental Technological Research, Polish Academy of Sciences, 02-106, Pawińskiego 5B, \\ Warsaw, Poland, kgolasin@ippt.pan.pl \\ ** Toyota Central Research \& Development Laboratories, Inc., Nagakute Aichi, 480-1192 Tokio, Japan, \\ e-mail: e0646@mosk.tytlabs.co.jp \\ *** Department of Mechanical Engineering, College of Engineering, Ibaraki University, 4-12-1 Nakanarusawa, \\ Hitachi, 316-8511, e-mail: kuramoto@mx.ibaraki.ac.jp
}

\begin{abstract}
Results of initial investigation of thermomechanical couplings in innovative $\beta$-Ti alloy called Gum Metal subjected to tension are presented. The experimental set-up, consisting of testing machine and infrared camera, enabled to obtain stress-strain curves with high accuracy and correlate them to estimated temperature changes of the specimen during the deformation process. Both ultra-low elastic modulus and high strength of Gum Metal were confirmed. The infrared measurements determined average and maximal temperature changes accompanying the alloy deformation process, allowed to estimate thermoelastic effect, which is related to the alloy yield point. The temperature distributions on the specimen surface served to analyze strain localization effects leading to the necking and rupture.
\end{abstract}

\section{Motivation}

Gum Metal, a new class of $\beta$-type multifunctional titanium alloys, has attracted considerable attention in the past decade due to its outstanding mechanical properties. The underlying mechanisms of its excellent performance are still unclear. The literature reports have not covered thermographic analysis of the alloy so far. Since infrared techniques and studies of thermomechanical couplings are a great tool for better understanding of mechanical behavior and phenomena occurring in materials the present research aimed at conducting thermomechanical and thermographic investigation of Gum Metal during tension.

\section{Introduction}

Gum Metal is a $\beta$-type Ti-based superalloy developed in Japan and reported first in 2003 [1]. Three electronic parameters were proposed for providing $\beta$ phase stability: (1) a compositional average valence number (e/a) of about 4.24; (2) a bond order (Bo value) of about 2.87; and (3) a "d" electron-orbital energy level (Md value) of about $2.45 \mathrm{eV}$. In addition, the oxygen concentration in the alloy is restricted to a range between 0.7 and 3.0 at.\% [1]. Typical compositions meeting these requirements are: $\mathrm{Ti}-12 \mathrm{Ta}-9 \mathrm{Nb}-3 \mathrm{~V}-6 \mathrm{Zr}-1.5 \mathrm{O}$ or $\mathrm{Ti}-20 \mathrm{Nb}-3.5 \mathrm{Ta}-3.4 \mathrm{Zr}-1.2 \mathrm{O}$. The fabrication route of Gum Metal includes powder sintering technique and processing by cold rolling. Both the fabrication route and the chemical composition strongly influence the superalloy characteristics. Gum Metal is known by the following outstanding properties: ultra-low elastic modulus with very high strength, rubber-like Poisson's ratio, superelastic nature - one digit higher in nonlinear elastic deformation $(\approx 2.5 \%)$ when compared to other metallic materials, super-plastic nature allowing cold plastic working without hardening up to $\approx 90 \%$, very low linear coefficient of thermal expansion (similar to Invar) and a constant elastic modulus in the temperature range from $-200^{\circ} \mathrm{C}$ to $+250^{\circ} \mathrm{C}$ (similar to Elinvar) [1-4]. The density of Gum Metal equals around $5.6 \mathrm{~g} / \mathrm{cc}$ which locates it between steels and aluminium alloys. The amount of oxygen in Gum Metal significantly changes its microstructure, mechanical and thermomechanical properties [7, 8, 11, 15]. Deformation mechanisms occurring in Gum Metal are unconventional and still unclear. First they were reported to be dislocation-free and caused by changes in microstructure during elastic deformation of Gum Metal namely by: lattice rotations, giant faults and nano-disturbances [3, 4]. However in further studies dislocation slips were observed in Gum Metal subjected to tension fabricated by research group [11]. Moreover the presence of secondary phases i.e. hexagonal $\omega$ and orthorhombic $\alpha$ " was detected $[12,13]$ and even said to be the origin for the unique properties i.e. the nonlinear elasticity, constant thermal coefficient in cold-worked Gum Metal. Excellent mechanical properties, namely high elasticity and flexibility of rubber combined with strength of metal make Gum Metal a very interesting material for a number of applications. Gum Metal has been applied in automotive, aerospace and precision industries. Since it is highly biocompatible there are numerous ongoing studies on using Gum Metal for implants and medical equipment [9, 10]. 


\subsection{1/qirt.2016.038}

\section{Experimental details}

The experimental set-up designed for the Gum Metal tension tests consisting of the MTS Testing Machine and Flir Co Phoenix Infrared System is depicted in figure $1 \mathrm{a}$. The fast and sensitive infrared camera recorded the infrared radiation from the specimen surface during the deformation process, which allowed to get its average and maximal temperature changes in contactless manner. The obtained data were used to analyze effects of thermomechanical couplings accompanying the alloy loading. The camera parameters were as follows: a wavelength range $3 \mu \mathrm{m} \div 5 \mu \mathrm{m}$, maximal frequency used in the experiment $538 \mathrm{~Hz}$, window size $160 \times 256$ pixels, thermal sensitivity up to $0.02^{\circ} \mathrm{C}$. A technical drawing presenting a specimen designed for Gum Metal tension tests conducted in the present work is shown in figure $1 \mathrm{~b}$, meanwhile a photograph of the specimen used in the test is depicted in figure $1 \mathrm{c}$.

a)

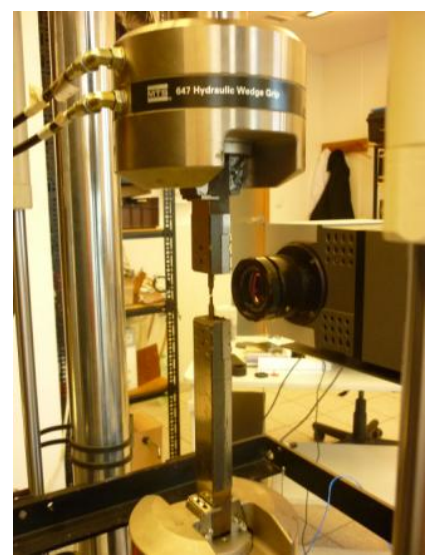

b)

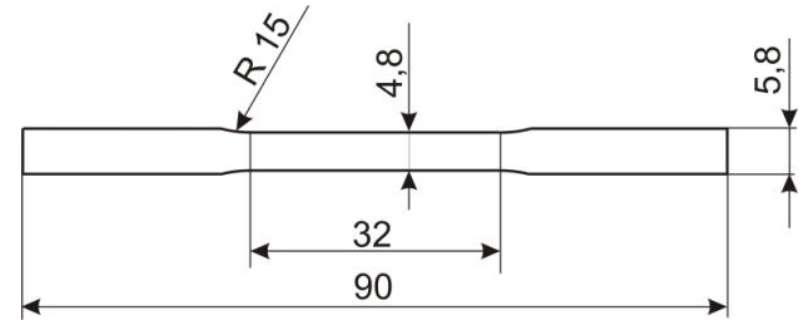

c)

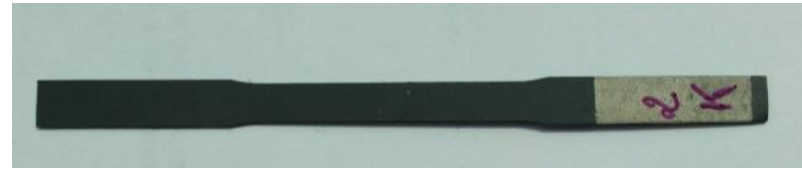

Fig. 1.: a) Experimental set-up; b) Technical drawing and c) Photograph of Gum Metal specimen.

The stress-strain curves for two Gum Metal kinds (fabricated with different technological parameters) and stainless steel subjected to tension at the strain rate of approximately $10^{-2} \mathrm{~s}^{-1}$ until rupture are depicted in figure 2 a. The comparison of stress-strain graphs for three materials proves the outstanding elastic behaviour for the Gum Metal, since its maximal strength is higher while the Young's modulus is significantly lower in comparison to steel. Interestingly the fabrication method has a great influence on the Gum Metal mechanical characteristics, namely kind 1 shows shorter plastic deformation range and higher strength when compared to kind 2. The stress-strain graph with maximal and average specimen temperature changes of Gum Metal (kind 2) strained until rupture is shown in figure 2 b. It can be noticed in figure $2 \mathrm{~b}$ that the maximal average temperature drop $(\approx 0.20 \mathrm{~K})$ in the specimen occurs significantly earlier than the limit of the reversible deformation $(\approx 930 \mathrm{MPa}$ ) macroscopically estimated. It means that such a large limit of the reversible elastic deformation (nonlinear), highlighted as the Gum Metal "super" property [1-4], originates from other deformation mechanisms and probably cannot be described by the Lord Kelvin formula [5, 6, 14]. The maximal temperature growth accompanying the specimen rupture is high and equals $95.5 \mathrm{~K}$. It is related to strong plastic localization of the deformation ending with rupture at the strain of around 0.18 .

a)

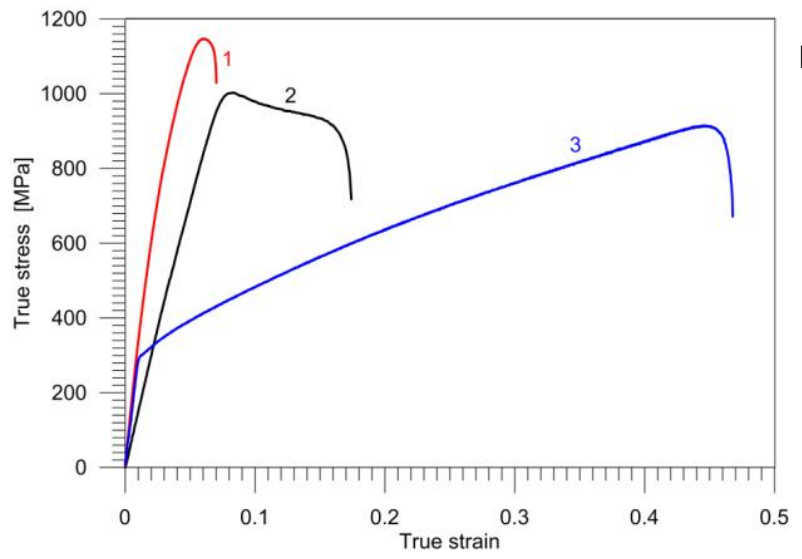

b)

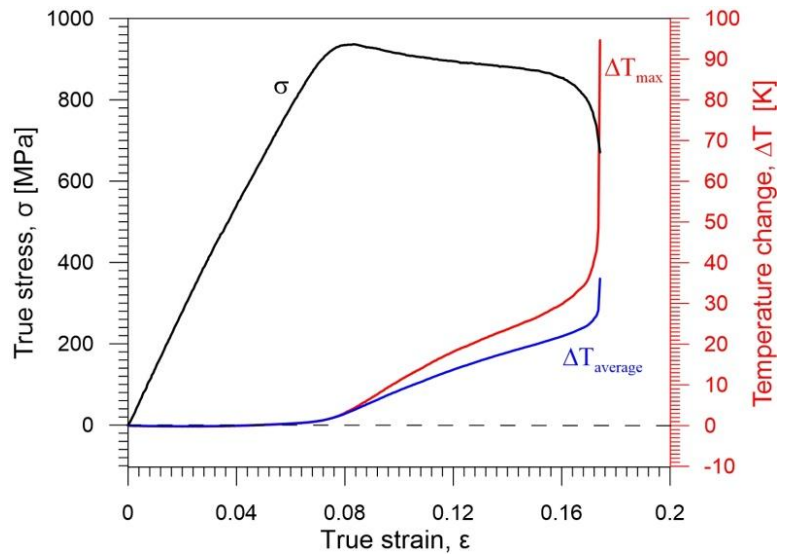

Fig. 2: a) Stress-strain curves comparison for two Gum Metal kinds (1-grey, 2-black) fabricated in different ways and stainless steel (3) subjected to tension until rupture at strain rate of $10^{-2} \mathrm{~s}^{-1}$; b) Stress-strain average and maximal temperature changes obtained for Gum Metal (kind 2) during tension at strain rate of $2.4 \times 10^{-2} \mathrm{~s}^{-1}$. 


\subsection{1/qirt.2016.038}

However different mechanical behaviors of two Gum Metal kinds have been observed, this work focuses on comprehensive analysis of thermomechanical characteristics of Gum Metal kind 1. Figures 3 and 4 present results recorded during tension of the Gum Metal (kind 1) at two strain rates of $10^{-2} \mathrm{~s}^{-1}$ and $10^{-3} \mathrm{~s}^{-1}$. Plots of stress, strain and average temperature changes vs. time for the two strain rates are shown in figures $3 \mathrm{a}$ and $3 \mathrm{~b}$.

a)



b)

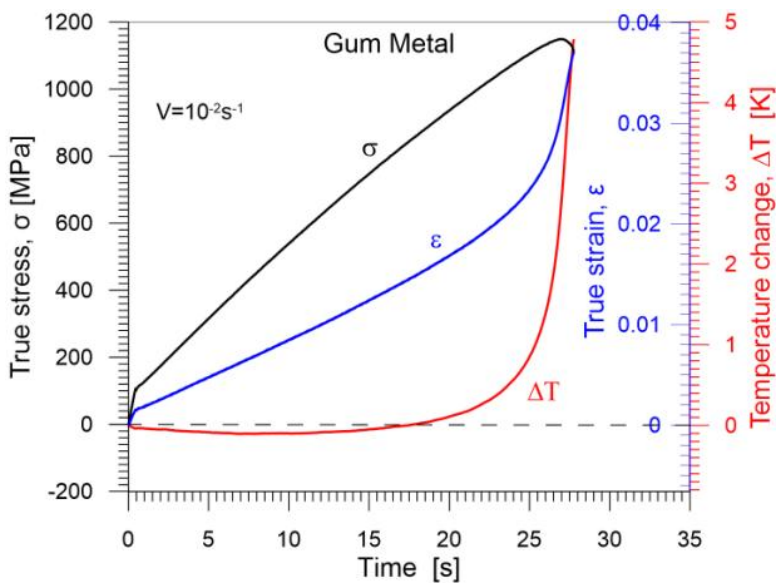

Fig. 3: Comparison of the thermomechanical results: stress, strain and average temperature changes vs. time obtained during tension of Gum Metal kind 1 at two strain rates of (a) $10^{-3} \mathrm{~s}^{-1}$ and (b) $10^{-2} \mathrm{~s}^{-1}$ until rupture.

a)



c)

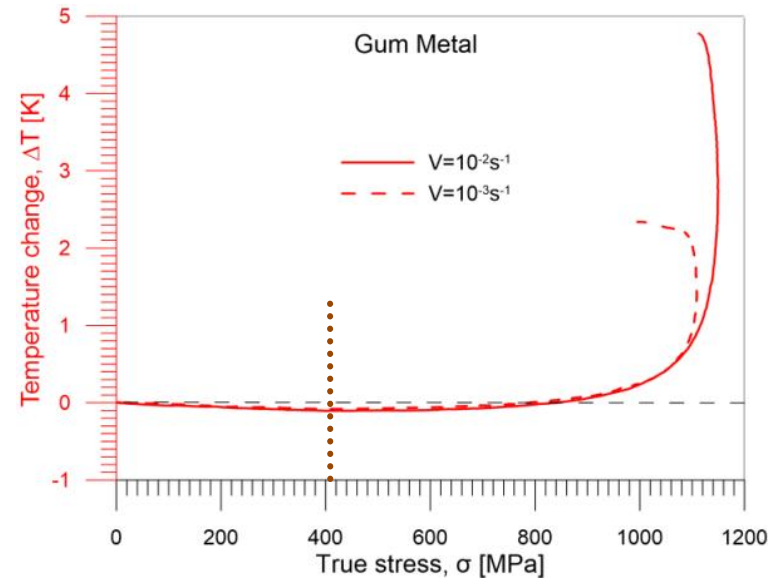

b)


Fig. 4: Comparison of the thermomechanical results obtained during tension of Gum Metal (kind 1) until rupture (a, b, c) at the strain rates of $10^{-2} \mathrm{~s}^{-1}$ (dashed line) and $10^{-3} \mathrm{~s}^{-1}$ (solid line): a) stress vs. strain, b) temperature change vs. strain, c) temperature change vs. stress and d) temperature change vs. stress in the initial stage of loading; dotted lines point where maximal drop in average temperature change occurs. 


\subsection{1/qirt.2016.038}

The strain rates applied in the tests influenced the mechanical behavior of the specimens. Higher maximal stress value of $1150 \mathrm{MPa}$ has been obtained for the strain rate of $10^{-2} \mathrm{~s}^{-1}$ whereas for the strain rate of $10^{-3} \mathrm{~s}^{-1}$ the maximal stress value obtained has equalled $1109 \mathrm{MPa}$ as presented in figure 4 a. Maximal average temperature drops of $-0.11 \mathrm{~K}$ and $-0.08 \mathrm{~K}$ related to stress values of $405 \mathrm{MPa}$ and $422 \mathrm{MPa}$ have been measured for the strain rates of $10^{-2} \mathrm{~s}^{-1}$ and $10^{-3} \mathrm{~s}^{-1}$, respectively and presented in graphs in figures $4 \mathrm{~b}-\mathrm{d}$. Maximal average temperature growth at the strain rate of $10^{-2} \mathrm{~s}^{-1}$ has equalled $4.79 \mathrm{~K}$ and has been higher in comparison to the value of $2.34 \mathrm{~K}$ obtained at the strain rate of $10^{-3} \mathrm{~s}^{-1}$ as shown in figure $4 \mathrm{~b}$ and $4 \mathrm{c}$. Critical values of Gum Metal thermomechanical properties from plots presented in figures $4 \mathrm{a}-\mathrm{d}$ are listed in table 1 .

Table 1. Critical values of Gum Metal thermomechanical properties obtained during tension tests at strain rates of $10^{-3} \mathrm{~s}^{-1}$ and $10^{-2} \mathrm{~s}^{-1}$

\begin{tabular}{|c|c|c|c|c|}
\hline Strain rate & Max. stress & $\begin{array}{c}\text { Max. temperature } \\
\text { drop }\end{array}$ & $\begin{array}{c}\text { Stress at max. } \\
\text { temperature drop }\end{array}$ & $\begin{array}{c}\text { Max. Temperature } \\
\text { growth }\end{array}$ \\
\hline $10^{-2} \mathrm{~s}^{-1}$ & $1150 \mathrm{MPa}$ & $-0.11 \mathrm{~K}$ & $405 \mathrm{MPa}$ & $4.78 \mathrm{~K}$ \\
\hline $10^{-3} \mathrm{~s}^{-1}$ & $1109 \mathrm{MPa}$ & $-0.08 \mathrm{~K}$ & $422 \mathrm{MPa}$ & $2.34 \mathrm{~K}$ \\
\hline
\end{tabular}

The temperature distributions (thermograms) on the specimens surface of the Gum Metal (kind 1) at various deformation stages with stress-strains graphs for two strain rates of $10^{-3} \mathrm{~s}^{-1}$ and $10^{-2} \mathrm{~s}^{-1}$, are demonstrated in figure 5 and 6 , respectively. The following characteristic points of the graphs were selected to show the corresponding temperature distributions for the subsequent stages of the tensile test at the strain rate of $10^{-3} \mathrm{~s}^{-1}$ (figure 5):

(0) the beginning of elastic deformation (start of experiment);

(1) the end of linear elastic regime (decrease in temperature);

(2) the end of nonlinear elastic regime;

(3) the beginning of plastic regime;

(4) intermediate plastic deformation stage, reaching maximal stress;

(5) advanced plastic deformation stage;

(6) just before rupture;

(6a) just after rupture;

(7) fracture of the specimen (end of experiment).

The temperature variation plot and the thermograms $(0)$ and $(1)$ show that in the linear elastic regime the maximal temperature drop is observed. Subsequently, the temperature starts increasing slowly till the end of the nonlinear elastic stage (2) and it is distributed equally on the specimen surface. Following through the plastic regime via thermograms (3), (4) and (5); the temperature rises more significantly and its distribution starts being more concentrated. The thermograms (6) and (6a) show development of the strain localization, characterized by the highest local temperature increase, leading to the specimen rupture in thermogram (7).

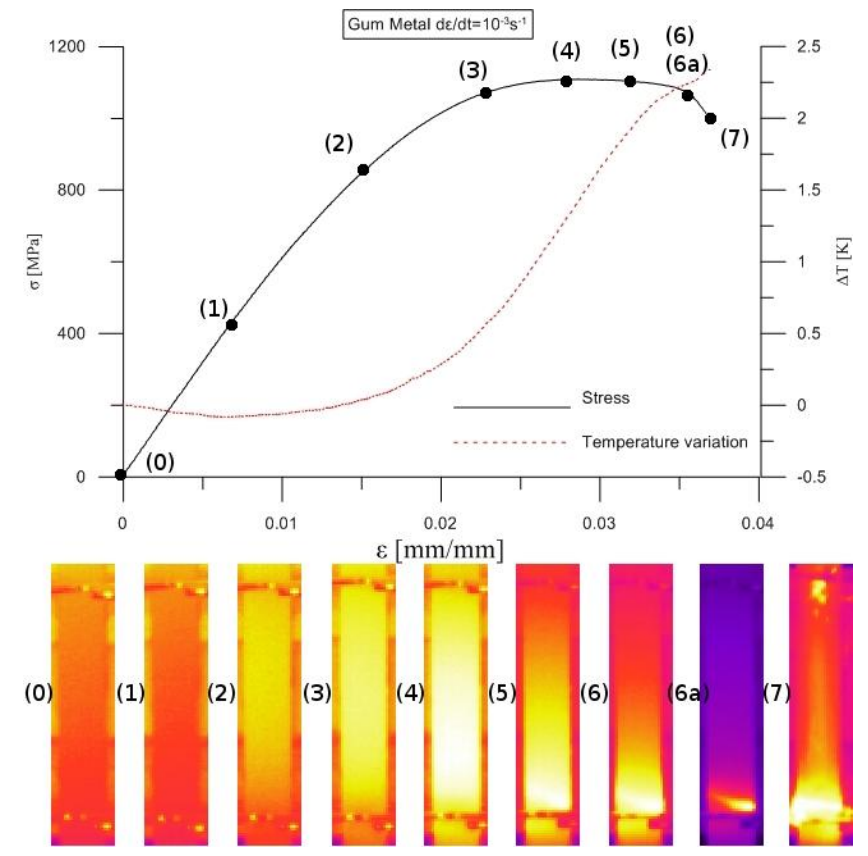

Fig. 5: Stress-strains curve with set of thermograms for the Gum Metal specimen correlated to their deformation stages for strain rate of $10^{-3} \mathrm{~s}^{-1}$. 
Figure 6 illustrates the stress-strain plot for the tensile test of the Gum Metal specimen carried out at the strain rate of $10^{-2} \mathrm{~s}^{-1}$. The characteristic points selected to show and analyze the corresponding thermograms are as follows:

(0) the beginning of elastic deformation (start of experiment);

(1) the end of linear elastic regime (decrease in temperature);

(2) the end of nonlinear elastic regime;

(3) intermediate plastic deformation stage, reaching maximal stress;

(4) advanced plastic deformation stage;

(5) just before rupture;

(5a) just after rupture;

(6) fracture of the specimen (end of experiment).

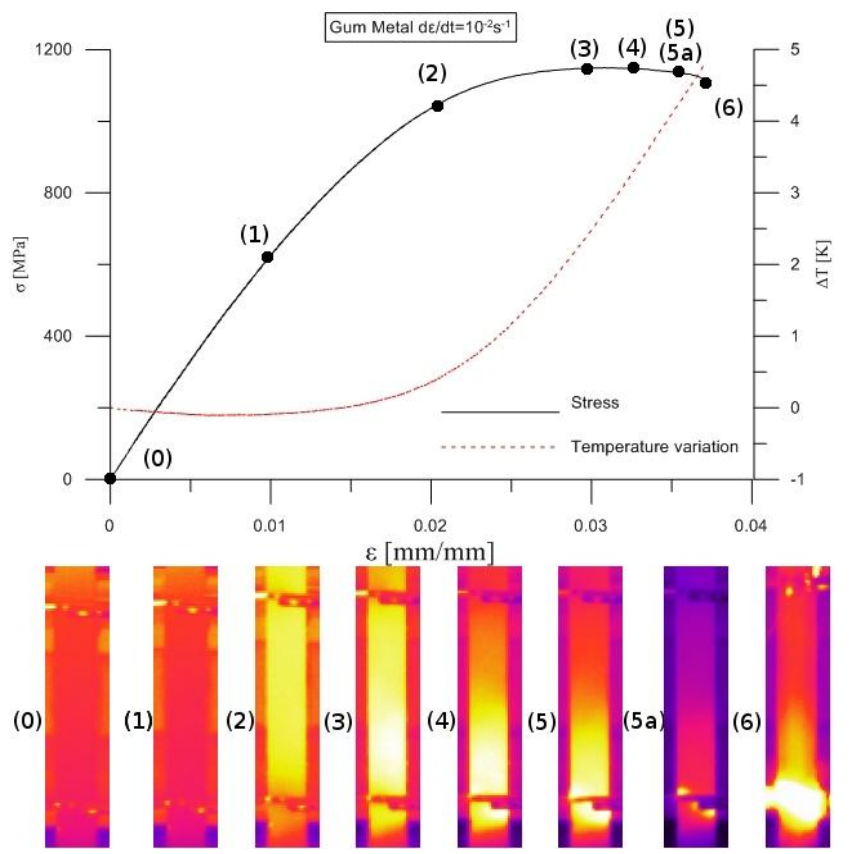

Fig. 6: Stress-strains curve with set of thermograms for the Gum Metal specimen correlated to their deformation stages for strain rates of $10^{-2} \mathrm{~s}^{-1}$.

Similarly to the previous analysis for the test carried out at the strain rate of $10^{-3} \mathrm{~s}^{-1}$ shown in figure 5 ; figure 6 indicates that the average temperature drop occurs in the linear elastic regime which is observed in two characteristic points for thermograms (0) and (1). Subsequently, the temperature starts growing till the end of the nonlinear elastic stage (2) and it is distributed uniformly on the specimen surface. Then, via the plastic regime, the temperature increases more significantly and its distribution starts being more concentrated which is shown in thermograms (3) and (4). The thermograms (5) and (5a) demonstrate the localization development characterized by the highest local temperature growth leading to the specimen rupture in thermogram (6).

\section{Discussion}

Outstanding mechanical performance of the Gum Metal alloy has been confirmed with the results presented in figure $2 \mathrm{a}$ and the measured values listed in table 1. One must take into consideration that the fabrication route plays a key role in the physical properties and mechanical characteristics of Gum Metal.

The average temperature of the specimens recorded during tensile tests presented in figures $2 \mathrm{~b}, 3-4$ linked to the deformation parameters allows to indicate a limit of the alloy reversible deformation, according to the thermodynamic laws and Lord Kelvin formula [6]. The maximal drop in average temperature marked by dotted line in figures 4 a-d measured for Gum Metal specimens occurs significantly earlier than the limit of the reversible deformation, macroscopically estimated. Thus the origin of such a large limit of the reversible nonlinear, elastic deformation must be another deformation mechanism, induced most likely by particular machining processes during the alloy fabrication.

The thermograms serve as a great tool to learn about the advanced deformation processes leading to the specimen necking and rupture. The localization illustrated in thermograms (7) and (6) in figures 5 and 6 , respectively is characterized by a high temperature increase. In these cases it occurred out of the gauge length, so the geometry change of the specimens has been applied for ongoing research. 


\subsection{1/qirt.2016.038}

\section{Concluding remarks}

Thermomechanical analysis of two kinds of Gum Metal subjected to tension at various strain rates has been presented. Unique mechanical characteristics i.e., low elastic modulus as well as high strength of the material have been confirmed. It has been shown that mechanical performance of Gum Metal depends on its fabrication history and strain rate applied in the test. The temperature plots with their maximal drop occurring before the end of the elastic limit recorded during deformations suggest that the nonlinear elastic behavior must origin from other mechanisms, dissipative, probably induced to the structure during the technological process.

The thermograms captured by a sensitive infrared camera showed effects of strain localization and high temperature concentration leading to necking and rupture.

More comprehensive mechanical tests, structure analysis, single crystal studies and numerical simulations of Gum Metal alloys will be considered for our further research.

\section{Acknowledgments}

The research has been carried out with the support of the Polish National Centre of Science under Grant No. 2014/13/B/ST8/04280. The authors are grateful to Dr. M. Maj for obtaining thermal characteristics and to L. Urbański for performing mechanical tests.

\section{REFERENCES}

[1] Saito T., Furuta T., Hwang J.H., Kuramoto S., Nishino K., Suzuki N., Chen R., Yamada A., Ito K., Seno Y., Nonaka T., Ikehata H., Nagasako N., Iwamoto C., Ikuhara Y., Sakuma T., Multifunctional Alloys obtained via a dislocation free plastic deformation mechanism, Science. - Vol. 300 no 5618 (2003), pp. 464-467, 2003.

[2] Miyazaki S., University of Tsukuba, Japan - Private Communications (2005-2014).

[3] Kuramoto S., Furuta T., Hwang J., Nishino K., Saito T., Elastic properties of Gum Metal, Materials Science and Engineering A. - Vol. 442 no 1-2 (2006), pp. 454-457, 2006.

[4] Furuta T., Kuramoto S., Morris J.W., Nagasako N., Withey E., Chrzan D.C., The mechanism of strength and deformation in Gum Metal, Scripta Materialia. - Vol. 68 no 10 (2013), pp. 767-772, 2013.

[5] Chrysochoos A., Infrared thermography applied to the analysis of material behaviour: a brief overview, Quantitative InfraRed Thermography Journal. - Vol. 9 no 2 (2012), pp. 193-208, 2012.

[6] Pieczyska E.A., Thermoelastic effect in austenitic steel referred to its hardening, Journal of Theoretical and Applied Mechanics. - Vol. 2 no 37 (1999), pp. 281-306, 1999 (Ph.D thesis).

[7] Wei Q., Wanga L., Fu Y., Qin J., Lu W., Zhang D., Influence of oxygen content on microstructure and mechanical properties of Ti-Nb-Ta-Zr alloy, Materials and Design. - Vol. 32 no 5 (2011), pp. 2934-2939, 2011.

[8] Wei L.S., Kim H.Y., Miyazaki S., Effects of oxygen concentration and phase stability on nano-domain structure and thermal expansion behavior of Ti-Nb-Zr-Ta-O alloys, Acta Materialia. - Vol. 100 (2015), pp. 313-322, 2015.

[9] Gordin D.M., Ion R., Vasilescu C., Drob, Cimpean A., Gloriant T., Potentiality of the "Gum Metal" titanium-based alloy for biomedical applications, Materials Science and Engineering C. - Vol. 44 (2014) pp. 362-370, 2014.

[10] Niinomi M., Nakai M., Hieda J., Development of new metallic alloys for biomedical applications, Acta Biomaterialia. Vol. 8 (2012), pp. 3888-3903, 2012

[11] Besse M., Castany P., Gloriant T., Mechanisms of deformation in gum metal TNTZ-O and TNTZ titanium alloys: a comparative study on the oxygen influence, Acta Materialia. - Vol. 59 (2011), pp. 5982-5988, 2011.

[12] Talling R.J., Dashwood R.J., Jackson M., Dye D., On the mechanism of superelasticity in gum metal, Acta Materialia. - Vol. 57 (2009), pp. 1188-1198, 2009.

[13] Tane M., Nakano T., Kuramoto S., Niinomi M., Takesue N., Nakajima H., $\omega$ Transformation in cold-worked Ti-Nb$\mathrm{Ta}-\mathrm{Zr}-\mathrm{O}$ alloys with low body-centered cubic phase stability and its correlation with their elastic properties, Acta Materialia. - Vol. 61 no 1 (2013), pp. 139-150, 2013.

[14] Pieczyska E.A., Maj M., Furuta T., Kuramoto S., Gum Metal - unique properties and results of initial investigation of a new titanium alloy - extended paper. Advances in Mechanics: Theoretical, Computational and Interdisciplinary Issues Keiber et at. (Eds) Taylor \& Francis Group, London, ISBN 978-1-138-02906-4, pp. 469-472, 2016.

[15] Nagasako N., Asahi R., Isheim D., Seidman D.N., Kuramoto S., Furuta T., Microscopic study of gum-metal alloys: A role of trace oxygen for dislocation-free deformation, Acta Materialia. - Vol. 105 (2016) pp. 347-354, 2016. 